\title{
Corpos e percepções de um tempo que passa: reflexões sobre gênero e movimentos do tempo em Sou Mais Eu, Junior e Men's Health Portugal
}

\author{
Bodies and perceptions of a passing time: reflections about gender and \\ time flow in Sou Mais Eu, Junior and Men's Health Portugal
}

\section{Cuerpos y percepciones de un tiempo que pasa: reflexiones sobre género y movimientos del tiempo en Sou Mais Eu, Junior y Men's Health Portugal}

\author{
Felipe Viero Kolinski Machado ${ }^{1, a}$ \\ felipeviero@gmail.com | http://orcid.org/0000-0002-8051-126X
}

Juliana Soares Gonçalves ${ }^{2, b}$

julianasoares.goncalves@gmail.com | https://orcid.org/0000-0003-3950-7450

${ }^{1}$ Universidade Federal de Ouro Preto. Ouro Preto, MG, Brasil.

2 Universidade Federal de Minas Gerais. Belo Horizonte, MG, Brasil.

a Doutorado em Ciências da Comunicação pela Universidade do Vale do Rio dos Sinos.
b Mestrado em Comunicação Social pela Universidade Federal de Minas Gerais.

\section{Resumo}

A partir das revistas Sou Mais Eu, Junior e Men's Health Portugal, segmentadas, respectivamente aos públicos feminino e de classe popular, gay e masculino heterossexual, e com base em discussões relativas ao gênero, aos movimentos do tempo e à sexualidade, o presente artigo propõe uma reflexão acerca dos sentidos então acionados sobre a relação entre os corpos e a passagem do tempo. Ainda que o corpo que se insere nos padrões estabelecidos de beleza seja relevante para Sou Mais Eu, de modo geral, as vivências cotidianas e os desafios narrados pelas leitoras parecem ser mais estruturantes, em Junior e em Men's Health Portugal, o envelhecimento (ou o não envelhecimento, mais propriamente falando) são compreendidos a partir de uma lógica que insere o corpo como essencial naquilo que se refere ao acesso a uma posição dominante. Ser jovem, aí, representa um elemento central no que tange à aquisição de uma posição hegemônica de masculinidade.

Palavras-chave: Gênero; Movimentos do tempo; Sexualidade; Narrativas; Revista.

\begin{abstract}
Based on the magazines Sou Mais Eu, Junior and Men's Health Portugal, segmented, respectively, to the public feminine and from a popular class, gay and masculine and heterosexual, and based, as well, on the discussions about gender, time flow and sexuality, this article proposes a reflection about the senses that are moved about the body and about the passage of time. Although the body that is inserted in the established standards of beauty is relevant, for Sou Mais Eu, in general, the daily experiences and the challenges narrated by the readers, seem to be more important, in Junior and Men's Health Portugal, to get old (or not get old, more properly speaking) are understood from a logic that inserts the body as an essential in what concerns access to a dominant position. Being young, there, represents a central element in the acquisition of a hegemonic position of masculinity.
\end{abstract}

Keywords: Gender; Time flow; Sexuality; Narrative; Magazine. 


\section{Resumo}

A partir de las revistas Sou Mais Eu, Junior e Men's Health Portugal, dirigidas, respectivamente a las mujeres de clase popular, a los gays y a los hombres heterosexuales, y basado en las discusiones relacionadas con el género, los movimientos del tiempo y la sexualidad, este artículo se propone a una reflexión acerca de los sentidos movidos sobre el cuerpo y sobre el paso del tiempo. Aunque el cuerpo injerido dentro de los padrones de belleza sea relevante, para Sou Mais Eu, en general, la experiencia cotidiana y los problemas narrados por las lectoras, parece ser más importante. En Junior y en Men's Health Portugal, el envejecimiento (o el no envejecimiento, por así decir) se entienden a partir de una lógica que inserta el cuerpo como esencial a lo que se refiere al acceso a una posición dominante. Es decir, ser joven, en estas revistas, representa un elemento central cuando se refiere a la adquisición de una posición hegemónica de masculinidad.

Palabras clave: Género; Movimientos del tiempo; Sexualidad; Narrativa; Revista.

Contribuição dos autores:

Concepção e desenho do estudo: Kolinski Machado FV, Gonçalves JS.

Aquisição, análise e interpretação dos dados: Kolinski Machado FV, Gonçalves JS.

Redação do manuscrito: Kolinski Machado FV, Gonçalves JS.

Revisão crítica do conteúdo intelectual: Kolinski Machado FV, Gonçalves, JS.

Declaração de conflito de interesses: Este trabalho não apresenta conflito de interesses

Fontes de financiamento: Coordenação de Aperfeiçoamento de Pessoal de Nível Superior (Capes) e Conselho Nacional de Desenvolvimento Científico e Tecnológico (CNPq).

Considerações éticas: A todos os entrevistados e entrevistadas consultados foi apresentado um termo de consentimento livre e esclarecido e todos concordaram em participar da pesquisa e em terem seus nomes e cargos divulgados.

Histórico do artigo: Submetido: 09.jan.2018 | Aceito: 26.mar.2018 | Publicado: 29.jun.2018

Apresentação anterior: Discussões iniciais acerca do artigo foram realizadas no evento "Historicidades nos Processos Comunicacionais: V Encontro de Grupos de Pesquisa Brasileiros", realizado na Universidade Federal de Ouro Preto (UFOP) em junho de 2017.

Licença CC BY-NC atribuição não comercial. Com essa licença é permitido acessar, baixar (download), copiar, imprimir, compartilhar, reutilizar e distribuir os artigos, desde que para uso não comercial e com a citação da fonte, conferindo os devidos créditos de autoria e menção à Reciis. Nesses casos, nenhuma permissão é necessária por parte dos autores ou dos editores. 


\section{Introdução}

O tempo passa. Sempre. Seu transcorrer, porém, é tomado de diferentes modos e impacta distintos sujeitos de formas que são particulares. Constatar, então, a relação que se estabelece entre os corpos e as passagens do tempo e compreender de quais maneiras singulares múltiplos sentidos são mobilizados a partir do discurso de determinadas revistas constitui-se no mote desse texto.

A partir de pesquisas anteriormente desenvolvidas ${ }^{1,2,3}$, as quais já tratavam de questões relativas aos gêneros, às temporalidades, às sexualidades e à mídia impressa segmentada, agora, nesse texto, almeja-se, de modo mais específico, perceber como mulheres, gays e homens heterossexuais podem/devem (ou então como não podem/não devem) experienciar a passagem do tempo, envelhecer e vivenciar a velhice (ou a não velhice) a partir do discurso constituído em Sou Mais Eu (revista brasileira voltada às mulheres de classe popular e que possui no testemunho de leitoras uma de suas bases), em Junior (revista brasileira segmentada ao público gay) e em Men's Health Portugal (revista portuguesa segmentada ao público masculino heterossexual).

Faz-se necessário sinalizar, contudo, que o movimento analítico aqui proposto não consiste em uma tentativa de comparação entre as revistas. Os lugares a partir dos quais esses discursos são produzidos, bem como os públicos aos quais eles se voltam, explicitam idiossincrasias que convêm serem consideradas. O que postulamos, pois, é que, tais publicações, ao tecerem sentidos sobre corpos e sobre vivências tão distintos, fornecem pistas importantes sobre como a passagem do tempo e a velhice (ou a não-velhice) são atravessados por ordens de gênero e pelas suas intersecções.

Para que o movimento de pesquisa proposto se fizesse possível, adotamos metodologicamente como lentes de análise a discussão de Paul Ricoeur ${ }^{4}$ sobre a tessitura da intriga, definida como uma "operação fundamental de saber da experiência, a condição e modo pelo qual é possível viver o tempo, por um lado, e, por outro, dar sentido ao mundo", tal qual sugere Bruno Souza Leal ${ }^{5}$. Assim, entendemos as textualidades assumidas na condição de corpus como configurações narrativas que procuram organizar acontecimentos e coisas do mundo, de maneira a oferecer propostas de inteligibilidade para elas. A composição do que Ricoeur ${ }^{4}$ nomeia por intriga resulta do encadeamento narrativo de elementos heterogêneos, ou seja, de uma tentativa de atribuir concordância a elementos discordantes.

A tessitura da intriga é parte do que o autor chama de círculo ou espiral mimético, composto pelo mundo prefigurado (mímesis I), que diz do repertório do leitor conformado pelo mundo social e o que Marcela Farré ${ }^{6}$ denomina de representações do real e pressupostos de verdade; da tessitura da intriga (mímesis II), que é a configuração narrativa propriamente dita a partir do agenciamento dos elementos acionados para a composição do sentido; e da mímesis III, que corresponde a reconfiguração do mundo a partir da experiência narrativa.

A noção de mímesis oferece uma ampliação da concepção de texto, "que deixa de ser um local específico e passa a corresponder a um atravessamento social”, como postulam Carlos Alberto de Carvalho e Guilherme de Sant'Ana'. Dessa forma, partindo das contribuições da tríplice mímesis, em especial da ampliação da noção de texto, que deixa de ser estável e assume o caráter de ação, procuramos extrapolar a materialidade narrativa imediata das revistas tomadas, numa tentativa de investigar as peculiaridades da construção narrativa das percepções dos movimentos do tempo e dos processos de envelhecimento e a consequente impressão de uma visão sobre a realidade que cerca e conforma tais tramas textuais. Quando a narrativa é compreendida como uma operação de concordância de elementos discordantes (como podem ser considerados os eventos convocados, personagens, temporalidades e espaços) mais do que quais e quando são apresentados tais elementos, nos interessa mais perceber quais são as relações e articulações de sentido propostas textualmente. 
A partir de tais considerações, nos dedicaremos a seguir a tecer apontamentos conceituais sobre questões que são caras a esse trabalho: as abordagens adotadas para melhor compreender o que tomamos por gênero e sexualidade e seus possíveis atravessamentos com a questão do tempo e do envelhecimento.

\section{Sobre gêneros, sexualidades e velhices (ou não velhices)}

Para que seja possível refletir sobre o passar do tempo, os corpos e suas relações com as construções de gênero, se faz importante, de início, tecer algumas elucidações sobre as bases teóricas que sustentarão nosso percurso. Para Judith Butler ${ }^{8}$, longe de serem substâncias permanentes, os sexos e os gêneros corresponderiam a categorias as quais teriam a sua coerência e relação estabelecida a fim de garantir a manutenção daquilo que Adrienne Rich ${ }^{9}$ definiu como "heterossexualidade compulsória". Na voz de Butler", o sexo e o gênero seriam construções políticas e ideológicas, sendo o próprio gênero o responsável pela constituição do sexo como algo que operaria no lugar do a-histórico e do pré-discursivo.

Tomando, então, o gênero como um contínuo fazer, como um devir e como uma atividade, e aproximandose da noção de performatividade, Butler ${ }^{8}$ dirá que ele se mostra "performativo no interior do discurso herdado da metafísica da substância - isto é, constituinte da identidade que supostamente é", consistindo em uma repetição que se dá no corpo, dentro de um quadro regulado e controlado, e que, ao longo do tempo, adquiriria a aparência de uma naturalidade.

Sendo a verdade interna do gênero uma fabricação, e, por conseguinte, sendo o gênero uma fantasia que é replicada nos corpos, ele não pode ser nem verdadeiro e nem falso, mas sim produzido como um "efeito de verdade de um discurso sobre a identidade primária e estável”.

Em um movimento que o aproxima, em certa medida, das proposições então expostas, Paul B. Preciado ${ }^{10}$ sugere que o sexo seja visto como um "produto do contrato sexual heterocentrado, cujas performatividades heteronormativas foram inscritas nos corpos como verdades biológicas" e, por meio de seu manifesto contrassexual, fomenta uma teoria do corpo que se situaria para além de binarismos (homem/mulher; heterossexualidade/ homossexualidade), que veria a sexualidade como uma tecnologia e o gênero, para além de performativo, como prostético.

A sexualidade, sob a perspectiva foucaultiana, pode ser compreendida como um dispositivo o qual objetivaria, por meio de linhas de força e de poder, dizer (determinada) verdade sobre o sexo, o qual abarcaria a história, vinculando a confissão da pastoral cristã à escuta clínica, que englobaria o dispositivo da aliança (o qual se referiria ao sistema de matrimônio e à transmissão de nomes e de bens) e que teria no corpo uma peça fundamental a ser utilizada, tendo como razão de existir "penetrar nos corpos de maneira cada vez mais detalhada e controlar as populações de modo cada vez mais global”"

Dessa maneira, como conformadores da experiência, modos de vivenciar e enunciar identidades de gênero e sexualidade conformariam também a maneira como as pessoas experienciam o passar do tempo e o envelhecimento de seus corpos. Tendo em vista tais considerações, para que o movimento de análise proposto seja possível, há que se falar sobre a cronologização do tempo, sobre a relação desse com os corpos e com as vidas e sobre a constituição de lugares desejados, ou indesejados, de serem ocupados pelos sujeitos.

Considerando como referência a discussão de Ricoeur ${ }^{4}$ sobre tempo e narrativa, levamos em conta a tomada do tempo como uma aporia, já que esse se estabelece em um não ser, uma vez que o passado não é mais, o futuro ainda não é, e o presente não tem permanência e extensão. "Contudo, falamos do tempo como tendo de ser: dizemos que as coisas por vir serão, que as coisas passadas foram e que as coisas presentes passam. Mas passar não é igual a nada. É notável que seja o uso da linguagem que sustente, provisoriamente, a resistência à tese do não ser"4.

Percebe-se, assim, que é só por meio da narrativa que se constitui pela linguagem que tornamos o tempo humano e dotado de sentido. A linguagem atua na articulação de um agir e de uma experiência. Dessa forma, ao narrar os processos de envelhecimento e as tentativas de retardá-lo ou de amenizar as 
consequências inerentes à carnalidade do corpo, as revistas tomadas operam na configuração de propostas de inteligibilidade sobre o passar do tempo, de forma que seja uma compreensão alcançável à nossa existência. Assim, os textos tomados estabelecem relações peculiares com o tempo que passa, acionando memórias e projetando futuros, configurando cronologias e compreensões do tempo a partir da vivência social compartilhada.

Logo, como indica Carvalho' ${ }^{12}$, em uma narrativa, não dizemos do tempo do acontecimento que nos propomos a relatar, mas do tempo da própria narrativa, já que quem narra se vale de estratégias como o alongamento ou o encurtamento de ações que tiveram maior ou menor importância no acontecimento, de acordo com os efeitos e ênfases de sentido pretendidos, assim como a tessitura de associações com ocorrências passadas e projeções de futuro. Ou seja, é desse tempo humanizado e configurado a partir de estratégias e propostas narrativas de sentido que tratamos aqui.

Sobre tais estratégias, ao falarem em "cronologização da vida", Kohli e Meyer ${ }^{13}$ ressaltam o fato de que, em face da consolidação da sociedade ocidental moderna e de um processo de individualização ao qual essa está relacionado, a institucionalização do curso da vida teria sido um aspecto essencial. "Uma forma de vida em que a idade era praticamente irrelevante foi suplantada por outra, em que a idade é uma dimensão fundamental na organização social"14.

De acordo com Luna Silva ${ }^{15}$, uma estabilização de categorias etárias; a percepção formal de que grupos homogêneos poderiam ser constituídos a partir de um recorte geracional e a constituição de identidades que dissessem, também, de uma faixa de idade, teriam se dado apenas ao longo dos séculos XIX e XX. É nesse sentido, por exemplo, que Pierre Bourdieu ${ }^{16}$ afirma que a juventude é apenas uma palavra, explicitando que tanto ela quanto seu antônimo, a velhice, não consistem em dados naturalmente estabelecidos, mas em constructos, resultantes de uma luta empreendida entre jovens e velhos.

No que tange à velhice, de modo mais específico, pode-se compreender que, apesar do envelhecimento ser um fato que transcende a história, o envelhecer nem sempre foi encarado da mesma maneira, modificandose mediante múltiplos contextos. Ao recorrer a diferentes textos que abordam a questão de um ponto de vista histórico e antropológico, Simone de Beauvoir ${ }^{17}$ expõe diferentes possibilidades de se incluir (ou de se excluir) aqueles que conseguissem sobreviver e, portanto, tornarem-se velhos.

Sendo, nas sociedades ocidentais, o resultado do investimento e da legitimação do discurso médico sobre o corpo envelhecido, a velhice, invariavelmente, passa a ser vista como a etapa da vida na qual o corpo se degenera. É em face deste contexto, portanto, que velhice, estando eminentemente relacionada à decrepitude e à perda de papéis sociais, é concebida não mais como um estágio natural do desenvolvimento biológico, mas como uma característica negativa a qual o sujeito não deve estar relacionado. A juventude, por outro lado, transforma-se em um valor a ser buscado, não mais apenas aos vinte ou trinta anos, mas em qualquer etapa da vida.

Indo ao encontro de Myriam Moraes Lins de Barros ${ }^{18}$, é possível perceber que ao eleger a juventude como a idade padrão da sociedade contemporânea, associa-se a ela, necessariamente, as noções de desenvolvimento, de evolução e de mudança. Igualmente, ao conceber a beleza como sinônimo de juventude, e a feiura como sinônimo de velhice, delegam-se espaços prévios às vidas e aos corpos dos sujeitos que ali forem inseridos. Ora, se assumir-se enquanto velho depende de cada um, ninguém optará por aderir a uma identidade que é deteriorada ${ }^{19}$. Ela será, previamente, irrealizável ${ }^{20}$.

Debert $^{14}$, então, ao discutir a reprivatização da velhice, diz de um processo que, ao tomá-la não como condição de determinada etapa do curso de vida, mas como a consequência da inaptidão daquele indivíduo que não conseguiu "manter-se jovem", a converte em uma responsabilidade de cada um. Logo, sendo a velhice um estado dos corpos que assume sentidos sociais, nos dedicaremos a seguir a convocar discussões que auxiliam na compreensão dos modos particulares como mulheres e homens percebem a passagem do tempo e estabelecem marcos temporais que o significam em suas vivências. Para tanto, tendo em vista 
que tais propostas narrativas de sentido conformam e são conformadas pela materialidade em questão, as revistas, nos parece fundamental tecer algumas considerações sobre elas.

\section{Sou Mais Eu, Junior e Men's Health Portugal: segmentação e constituição de identidades}

A revista, e ojornalismo dali advindo, lugares a partir dos quais nos propomos a refletir acerca das questões de gênero, de envelhecimento e de sexualidade que aqui são elencadas, possuem certas especificidades que convêm ser destacadas. Marília Scalzo ${ }^{21}$ definirá a revista como sendo "um veículo de comunicação, um produto, um negócio, uma marca, um objeto, um conjunto de serviços, uma mistura de jornalismo e entretenimento".

Como destaca Marcia Benetti ${ }^{22}$, a revista possuiria como elementos diferenciais ser segmentada, por público e por interesses; ser durável e colecionável; possuir características materiais e gráficas que a distingam (e que a singularizem) e estabelecer uma relação direta com o leitor. Para a autora, o jornalismo de revista, ainda, trabalharia com uma ontologia das emoções, ou seja, para além da informação em si, ele visaria a construir um vínculo afetivo com o leitor em questão. "Aquilo que leio, a revista que assino, a informação que me mantém conectado ao tempo presente ('meu' tempo, 'minha' sociedade, 'meus' desejos") constituem indicadores de minha concretude"22.

A segmentação, questão que nos é especificamente cara nessa pesquisa, apresenta-se como uma das questões importantes ao se refletir acerca das revistas e acerca do seu particular fazer. Seguindo as pistas de Frederico Tavares e de Reges Schwaab ${ }^{23}$, é possível compreender a revista como "um meio de comunicação cuja relação com a sociedade contribui para a formação de nichos de público a partir de segmentos sociais diversos".

A segmentação, como bem lembra Dulcilia Buitoni ${ }^{24}$, pressupõe divisão, grupos e um trabalho analítico e conceitual que se faz presente no momento da produção jornalística. Pensar a segmentação, nesse sentido, pressuporia tomá-la, para além de uma estratégia de marketing, como um fenômeno que diz de ecologias socioculturais. A autora apontará a existência de duas formas fundamentais de segmentação, a saber: por assunto, que diria da temática da revista em si (moda, automóveis, esportes), e por participação de um conjunto maior, em referência à operação, empreendida pela empresa de comunicação, em que as "variáveis básicas", como gênero, classe social e faixa etária, entrecruzam-se, compondo um novo projeto.

Avançando nesse sentido, ela lembrará que ao passo que a cultura de massa tenderia a gerar uma homogeneização do público, a segmentação traria implicada uma diferenciação que se daria a partir de consonâncias grupais. "Segmentar é separar para melhor compartilhar. Separar também é focar: uma aliança do racional com o desejo" 24 .

Tendo em vista as considerações sobre as revistas e seus processos de segmentação, nos parece fundamental localizar as publicações que tomamos por objeto na presente análise. A revista Sou Mais Eu é uma revista originada na Editora Abril, em 2006, que passou a ser produzida pela Editora Caras em 2014. Trata-se de uma publicação semanal, que tem como diferencial a composição das matérias por histórias de pessoas comuns, narradas em primeira pessoa, com temas variados e, muitas vezes, inusitados. Em 2015, a publicação pagou até mil reais (cerca de trezentos dólares) para que as leitoras contassem suas histórias de superação. Em cada matéria é possível saber quanto a narradora, geralmente uma mulher, recebeu pela participação. No contexto de sua criação, conforme observado no website da Editora Abril, o objetivo da revista era servir de palco para que as pessoas comuns pudessem contar suas 'histórias extraordinárias'. A revista emerge como uma publicação que se aproxima do público por ser construída a partir de relatos das próprias leitoras. Sou Mais Eu pretende assumir o papel de 'amiga','confidente' e incentivadora da superação e da busca da felicidade por contar histórias de 'gente como a gente'.

A destinatária da revista é uma mulher adulta, casada, principalmente da classe C (dados divulgados pela Editora Caras em 2016 apontam que 48\% das leitoras se encontram nesse extrato), com interesses 
que passam, principalmente, pela família, relação amorosa, desempenho sexual, beleza, vaidade, emagrecimento, animais de estimação, espiritualidade e geração de renda. As narrativas publicadas na Sou Mais Eu têm como fio condutor histórias de pessoas que superaram obstáculos diversos na vida, como a obesidade, a falta de vaidade, a baixa renda, a solidão, a depressão, humilhações e violências. O caminho encontrado por todas as protagonistas está baseado na determinação e empenho pessoal, que levam, quase invariavelmente, ao encontro de um modelo de felicidade.

Essencialmente narrada em primeira pessoa, a Sou Mais Eu se apropria dos testemunhos como estratégia de aproximação com o público, uma vez que se trata de pessoas comuns contando suas histórias para outras pessoas comuns, bem como para a produção de efeitos de verdade baseados na experiência de quem narra. Ao usar a primeira pessoa, compartilhando experiências íntimas com as demais leitoras, as narradoras criam em suas histórias o que Marín-Díaz"25 chama de "manto invisível de confidencialidade", que, quando firmado, dá a ver certa partilha entre narradora e leitora de determinada experiência de mundo, fazendo com que essas comunguem também da dimensão sensível das dores e necessidades articuladas narrativamente.

Já a revista Junior foi fundada em 2007, e no instante do encerramento de suas atividades, em 2015, correspondia a única revista impressa, de caráter jornalístico, voltada ao público gay no Brasil. Tendo em vista a leitura e a análise de suas edições, o acesso a diferentes trabalhos que também voltaram sua atenção a ela ${ }^{26-28} \mathrm{e}$, ainda, as entrevistas realizadas com os profissionais envolvidos em sua produção (editor, repórteres e fotógrafo), observou-se que, por mais que tenha passado por diferentes grupos editoriais e ainda que tenha sido editada e produzida por distintos profissionais, algumas de suas características se mantiveram ao longo dos anos. Voltando-se, de modo mais específico, a um público gay com poder aquisitivo mais elevado (ainda que na forma de um leitor ideal), a revista, majoritariamente, ao abordar aquilo que compreendia como 'universo gay', dizia de um conjunto de práticas e de vivências e de um tipo de masculinidade, de estética e de corpo bem específicos. Conforme se percebeu a partir das entrevistas realizadas, havia mais suposições do que certezas acerca do perfil dos leitores da revista. Junior não possuía pesquisas específicas que dissessem de sua audiência. A experiência era enunciada, então, por aqueles que a produziam, como fator que dava a ver a quem, de fato, Junior chegava, mostrando, inclusive, que ideias iniciais não se sustentavam. A fala de Felype Falcão ${ }^{29}$, que atuou como editor e como repórter da revista, é então ilustrativa. "Quando a Junior é concebida, a intenção é que ela seja como revistas como Out [revista gay estado-unidense] e como Têtu [revista gay francesa], revistas voltadas a um público gay que gostasse de consumir informação, que tivesse uma escolaridade maior, que tivesse condições financeiras melhores. A ideia era atingir esse público [...]. No decorrer da produção da revista, conforme íamos conhecendo o leitor, pelos lugares em que se vendia mais ou menos, pelo público que dava retorno, que escrevia, percebemos que nossos leitores não tinham tanta escolaridade quanto achávamos, nem tinham tanto dinheiro quanto imaginávamos. E percebemos, então, que era um outro cara que era o principal consumidor da nossa informação".

A revista Men's Health, por sua vez, foi fundada em 1987, nos Estados Unidos. Atualmente é a maior revista masculina do mundo, possuindo trinta e sete edições em sessenta e um países ${ }^{30}$. Em Portugal a revista existe desde 2001, sendo à época da pesquisa publicada pelo grupo Motorpress. Ainda que voltada a um público heterossexual, e ainda que traga o sexo como um forte elemento de sua receita, $\mathrm{MH}$, ao ser lançada, rompe com um lugar predeterminado às mídias segmentadas masculinas ao promover um deslocamento do desejo que passa, prioritariamente, do corpo da mulher (nesse nicho, em específico, ainda mais sexualizado) para um corpo masculino que deve ser almejado/construído pelos leitores ${ }^{31-33}$.Tal qual é apresentada na versão portuguesa de seu Media Kit, Men's Health é uma revista sobre homens, para homens, escrita para os ajudar a melhorar a qualidade de vida com informação prática e positiva. Acerca de seu público de leitores, pesquisas expostas no mesmo documento apontam que eles possuiriam uma média etária entre dezoito e quarenta e quatro anos, pertenceriam às classes A, B e C1 e, naquilo que se refere 
às profissões, integrariam quadros médios superiores, sendo trabalhadores qualificados e empregados de serviços e de comércio.

Consideradas as especificidades das revistas, nos concentraremos, em nossos próximos tópicos, na tentativa de compreensão dos processos de percepção temporal e envelhecimento que se dão a ver nos discursos tomados como corpus empírico do presente artigo.

\section{Feminino e percepção temporal nas páginas de Sou Mais Eu}

Para pensar nos processos de envelhecimento narrados pelas mulheres da revista Sou Mais Eu, considerar a dimensão do corpo se faz imprescindível. A partir do estabelecimento de padrões de beleza inatingíveis que ocupam, com frequência, os espaços midiáticos como lugares de sua propagação e consolidação, já não basta alcançar o corpo dos sonhos, mas é necessário, nessa condição, se fazer visto. Ao perseguir tais padrões, o corpo se mostra sempre inadequado, já que o culto à carne na sociedade contemporânea diz de um certo tipo de corpo específico, resultante de procedimentos e rituais que quase se aproximam dos religiosos, pois são fundados em suas próprias regras, cerimônias e expiações ${ }^{34}$.

O alcance do corpo modelo se apresenta como um desafio tão complexo que aqueles que conseguem aproximar a modelagem corpórea aos padrões se tornam dignos de ocupar o espaço dos media. As musas fitness e os homens musculosos são alguns dos exemplos da apropriação midiática da busca pelo corpo perfeito. Mais do que expostos para contemplação, os corpos exemplares são tomados como inspiração para adaptação de si mesmo, de modo que se possa ser observado de maneira semelhante e possa ser celebrado por seu corpo belo, torneado, jovem e magro. Nesse processo, o corpo na condição de matéria orgânica é sempre defeituoso e, por isso, sua adaptação demanda dedicação e esmero. A vivência da felicidade por meio da conquista do corpo perfeito é, invariavelmente, paradoxal, na medida em que não desperta apenas o prazer e a felicidade associados a uma dimensão encarnada. Ao contrário, o corpo como imperfeito e perecível por natureza, se constitui como fonte permanente de angústias e inquietação, sendo constantemente submetido a intensas rotinas, muitas vezes agressivas e dolorosas na busca pela adequação.

A busca pelo corpo modelo dá a ver a sua expressividade nas narrativas e nos modos de vida contemporânea quando observamos que a maior parte das capas da revista Sou Mais Eu do ano de 2015 (25 de 42) trazem como tema os casos de emagrecimento. Não existe dimensão corpórea que não possa ser adaptada. As narrativas da Sou Mais Eu abordam perspectivas diversas da busca pela beleza, que vão desde o emagrecimento (Figura 1), até dicas para cabelos sedosos, dentes brancos e lentes coloridas para mudar a cor dos olhos. O 'eu' aparece como massa orgânica manipulável, como se pode notar no título do relato de Silvana Ribeiro ${ }^{35}$ : "Sou quem eu quiser com lentes coloridas!". Ou seja, essa chamada faz emergir o valor máximo que atravessa esse modelo de felicidade: mediante o próprio esforço, o indivíduo pode ser quem quiser, seja na dimensão afetiva, emocional, profissional ou física. 


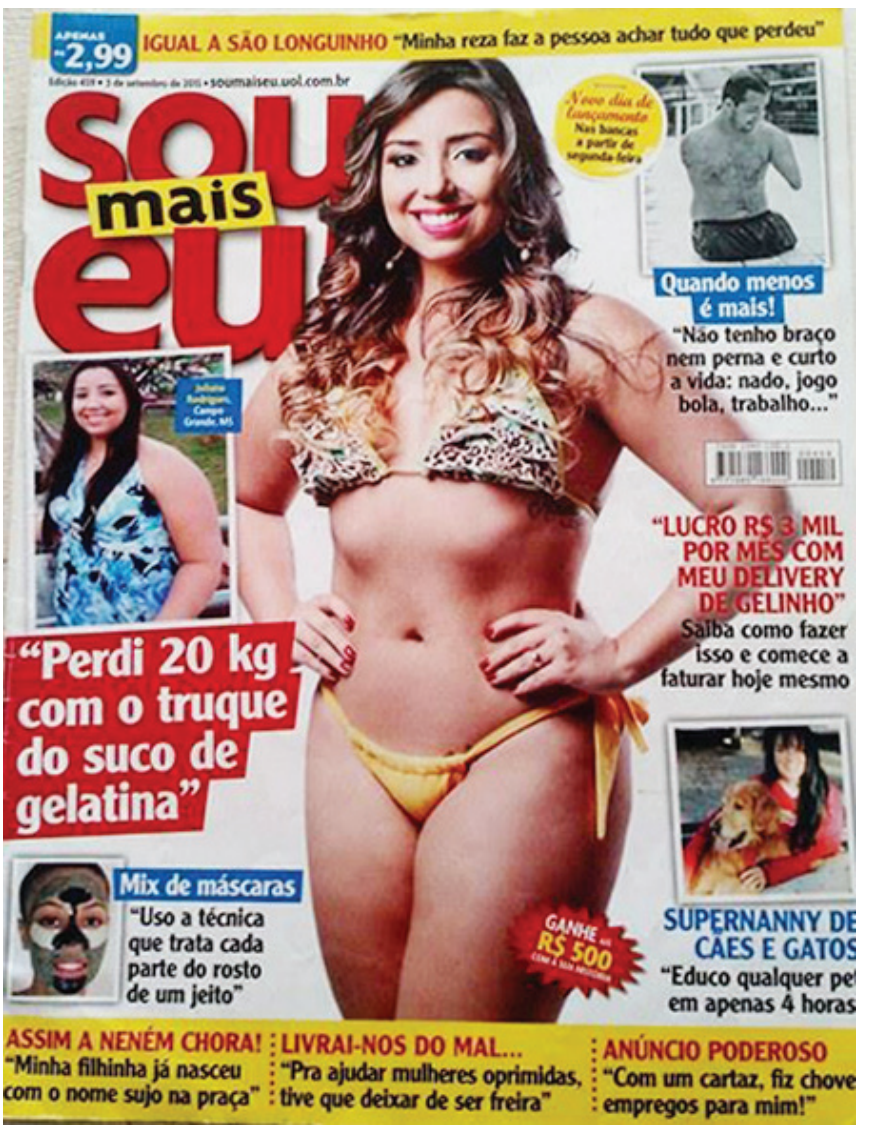

Figura 1 - O 'eu' como projeto

Fonte: Sou Mais Eu (2015)'.

No contexto neoliberal em que a individualidade assume lugar central, o corpo como resultado de um projeto de design epidérmico ${ }^{34}$ se constitui como uma espécie de vitrine da subjetividade contemporânea, ao passo que o alcance de certa visibilidade e o reconhecimento por meio do olhar do outro são essenciais como validadores do que se pretende ser. É a natureza orgânica da carne humana, sua consistência e viscosidade que são tomadas como um desafio a ser superado. Enquanto a vida permanece, observa-se uma luta interminável na tentativa de "dominar essa carnalidade incômoda, sempre imperfeita, flácida, gordurosa, enrugada, fatalmente submetida à dinâmica abjeta das secreções e da decomposição orgânica”" ${ }^{4}$. A cultura da boa forma persiste em uma luta constante contra a 'teimosia da carne' de maneira tão intensa que se aproxima de uma tentativa de desencarná-la, na busca por corpos virtuais. Nesse sentido, a ânsia pela autoestima como forma de felicidade opera na caça a todos os hábitos e comportamentos que podem afastar o indivíduo desse ideal. Ou seja, a simples existência em um tempo que passa, na condição de um corpo vivo, orgânico e perecível, é, de partida, uma desvantagem nessa missão, já que a direção natural corpórea aponta para a deterioração física.

Frente a tamanho desafio de modificar e retardar os processos orgânicos, aqueles que são bem-sucedidos na missão têm como recompensa o privilégio de ostentar o corpo como sinônimo de felicidade "nos mais diversos âmbitos da vida: sucesso profissional, prazer sexual, amor, beleza, bem-estar"34. Essa busca contemporânea pela felicidade que se materializa no alcance de um modelo de corpo perfeito está assentada na indústria da insatisfação. Assim, estamos inseridos em uma teia de valores que condena os indivíduos considerados feios, velhos e gordos, de maneira que qualquer um que esteja enquadrado nessas manifestações de insucesso é associado a falhas de caráter individual, "um erro na própria programação corporal, que se deveria evitar a qualquer custo ou, pelo menos, ocultar vergonhosamente da visão alheia”" ${ }^{4}$.

i Sou Mais Eu (Editora Caras). 2015 set. 03: Ed. 458. 
Já quando lançamos o olhar para o atravessamento do ser mulher e da percepção temporal das diferentes fases da vida, questões importantes se fazem ver nas páginas da revista Sou Mais Eu. Martins ${ }^{36}$, ao falar sobre a medição do tempo, ressalta como sendo elemento fundamental nesse processo as sensações relativas à experiência temporal. Da mesma maneira, Franch ${ }^{37}$ destaca como a classe, a geração e o gênero operam como lugares essenciais para que a passagem do tempo seja reconhecida. "Os lugares que determinam a idade social são sexualmente diferenciados, sendo o tempo vital das mulheres informado principalmente pela sua capacidade de procriação (consequentemente pelo seu valor no mercado matrimonial) e o dos homens por sua posição econômica (ou seja, pelo lugar ocupado no mercado de trabalho)".

No caso das mulheres jovens de baixa renda, a autora salienta acontecimentos como a primeira relação sexual, o casamento e o primeiro filho como sendo pontos de virada em suas biografias. Os chamados turning points são discutidos por Hareven ${ }^{38}$ como "avaliações subjetivas de continuidades e descontinuidades sobre o curso da vida [...]. Em alguns casos, os turning points são percebidos como mudanças críticas, em outros casos, como recomeço" ${ }^{8}$. Nas vivências femininas, é comum que acontecimentos vinculados à vida familiar, como a gravidez e o casamento, sejam tomados como pontos de virada da adolescência para a vida adulta. Mesmo com tais recorrências, não dizemos aqui que essas experiências se façam da mesma forma para todas. Cada mulher se apropria, (re)elabora e subverte tais acontecimentos na própria biografia com diferentes matizes, de maneira mais alinhada a sentimentos positivos ou negativos.

Franch ${ }^{37}$ chama atenção para a forma como, mesmo em contextos de emancipação, o ciclo de vida feminino tende a permanecer mais relacionado com as dimensões reprodutivas e sexuais, em detrimento da educação e da profissionalização, por exemplo, que são mais frequentes na construção do masculino. Assim, mesmo nos casos em que a família possibilite às jovens o acesso à educação, o casamento e a reprodução ainda são tomados como a ordem natural das coisas, no que diz respeito à maneira como a vida delas será estabelecida. Logo, ao narrar a si, observa-se, por exemplo, o estabelecimento de certa periodização das transições femininas. Classificações como "moça", "mulher", "casada", "solteira", "mãe", vinculadas ao ciclo reprodutivo e sexual feminino são acionadas com mais frequência nas narrativas sobre a vida das mulheres do que categorias como "adolescente", "adulta" e "velha". Isso permite inferir que a percepção das etapas das vidas das mulheres está menos conectada a um passar do tempo cronológico do que aos pontos de virada descritos. Além disso, tais categorias pressupõem um tipo de classificação moral, já que ser "mãe solteira" tem uma valoração consideravelmente diferente do que ser "mulher casada".

Pensando, por exemplo, no que se configura como marcos de passagem para a vida adulta em determinados contextos, consideramos narrativas como a de Lucineide Santos ${ }^{39}$ emblemáticas. Ela foi estuprada aos 13 anos, ocasião em que foi obrigada a se casar com seu algoz, engravidou do primeiro filho aos 15 anos, e aos 22 anos já havia passado por quatro gravidezes. "Engravidei do meu primeiro filho aos 15 anos, mas nem isso amoleceu o coração do Abapuru. Ele abusou de mim durante todos os meses de gestação. Quando o bebê nasceu, uma menina, teve que dormir em uma banheira fria. Por isso, com três dias de vida, morreu".

O fato de uma adolescente de 15 anos ter ficado grávida em função de estupros repetidos do marido não faz problema na narrativa. A questão levantada se limita à primeira violência sofrida, de maneira que a partir do momento que Lucineide perde a virgindade em um estupro (mesmo que o episódio tenha acontecido quando ela tinha 13 anos) e se casa com seu agressor, ela se torna uma mulher adulta.

Essa passagem se contrapõe com a história contada por Catharina Doria, criadora do aplicativo Saipraláii, elaborado com o objetivo de mapear, colaborativamente, os locais onde mulheres de todo Brasil sofreram assédio. Aos 17 anos, ela relata estar concluindo o ensino médio e se preparando para viajar com os amigos. Aos 18 anos, Lucineide já estava casada há cinco e estava grávida pela segunda vez. Neste ponto é possível perceber como os atravessamentos interseccionais, como o gênero e a condição socioeconômica, podem

ii Saipralá [App]. São Paulo; [2015]. 
ser definidores da experiência temporal de ser mulher e de sua constituição como adulta. A passagem do tempo na história de Lucineide tem como principais marcadores as vivências tipicamente associadas ao feminino: a perda da virgindade no estupro sofrido, o casamento com seu agressor, o nascimento e a morte do primeiro filho, o nascimento dos outros oito filhos (ela teve outros quatro filhos de outras relações mais tarde) e a tentativa de estupro sofrida por uma das filhas pelo ex-companheiro.

Dessa forma, foi possível observar na maioria dos casos, em especial naqueles em que a protagonista era pobre e periférica, que as temporalidades construídas narrativamente nos relatos são recorrentemente relacionadas aos eventos de foro íntimo e afetivos, tipicamente associadas ao feminino. A passagem de tempo é frequentemente marcada pelo casamento, pela primeira relação sexual, pelo nascimento dos filhos e por passagens da vida afetiva e doméstica. Logo, é possível perceber que as questões de gênero são constitutivas das mais diversas dimensões das vivências femininas, atravessando seus corpos, a maneira como sentem e expressam seus sentimentos, a experiência temporal e a sua possibilidade de agência frente aos mais diversos acontecimentos.

Os turning points, ou pontos de virada, ou seja, experiências significativas que são capazes de redirecionar um caminho ou romper com certa condição instaurando algo novo, são elementos recorrentes nas narrativas analisadas, correspondendo ao que nomeamos de superação. A decisão de virar a mesa e modificar determinada realidade corresponde ao que se configura na narrativa como a ação capaz de fazer com que a narradora supere certa circunstância desfavorável, reordenando a própria vida. As narrativas aqui consideradas configuram relatos de superação de determinada situação a partir de um episódio que marca essa virada.

Em seu depoimento, Flávia Carvalho ${ }^{40}$, tatuadora de 30 anos, conta sobre o seu projeto de tatuar uma mulher vítima de violência, semanalmente, sem custos, com o objetivo de cobrir as cicatrizes das agressões, que vão desde marca de tiros, facadas e outros ferimentos. A realização da tatuagem é narrativamente constituída como um poderoso ponto de virada, comparado a um rito de apagamento das marcas das agressões vivenciadas, assim como da tristeza e do sofrimento dessas mulheres. "É extremamente gratificante fazer o que amo e ver que aquelas poucas horas redesenhando a pele dessas mulheres podem ser capazes de apagar anos de sofrimento, vergonha e tristeza. As mulheres chegam ao estúdio cabisbaixas, contando histórias trágicas, e saem de lá revigoradas, com um novo ânimo".

Ou, seja, enquanto a percepção da passagem do tempo, bem como da mudança relativa às diferentes fases da vida, se mostra menos cronológica e mais social para as mulheres da Sou Mais Eu, a questão do envelhecimento do corpo (e, principalmente, como evitá-lo) parece ser um dos pontos centrais das narrativas das revistas Junior e Men's Health Portugal.

\section{Sobre os caminhos para (não) envelhecer}

Para o sociólogo polonês Zygmunt Bauman ${ }^{41}$, frente a um período líquido, repleto de anseios, de inseguranças e de incertezas, buscar-se-iam, obstinadamente, manuais que, de modo seguro e prático, dissessem aos atores sociais sobre como se viver. Os sujeitos (aqui leitores) procurariam, pois, por alquimistas que pudessem lhes fornecer garantias, transformando "a incerteza da base em preciosa autossegurança". O que se veria, aí, seria um "surto de aconselhamento", no qual os indivíduos não mais precisariam de "pregadores para lhes dizer da fraqueza do homem e da insuficiência dos recursos humanos"41, mas clamariam, avidamente, por reafirmações daquilo que podem fazer e, principalmente, do modo como fazê-lo. E é nessa conjuntura que a mídia ocupa seu quinhão e que, tal qual será explicitado, Junior e Men’s Health Portugal dizem aos seus públicos específicos sobre como ser homem e, mais especificamente, sobre a necessidade de manter-se jovem por mais tempo (se não para sempre). 
Em pesquisa anteriormente desenvolvida ${ }^{2}$, que tomava os textos e imagens publicados e as falas dos agentes envolvidos em sua produção como discursos possíveis de serem estudados, constatou-se que, em relação aos sentidos que se constituem como possíveis acerca das masculinidades em Junior e em Men's Health Portugal, o reforço a um projeto de masculinidade dominante, ainda que na condição de cúmplice ${ }^{42}$, é a tônica de ambos os veículos. Apesar de voltadas para diferentes públicos (gays e homens heterossexuais), as duas publicações delimitam a constituição de um corpo espetacular ${ }^{43}$ como algo essencial para que esses sujeitos leitores possam, de fato, ocupar uma posição hegemônica. Esse corpo, então constituído, possui contornos bem definidos: é um corpo musculoso, é um corpo com pouca gordura, é um corpo sexualmente ativo, é um corpo em geral branco e, invariavelmente, é um corpo jovem (ou que traga marcas da juventude).

Junior, faz-se relevante destacar, traz a juventude explicitada em seu próprio título. Conforme menciona André Fischer ${ }^{44}$, fundador e primeiro editor da revista, acerca de seu título, "Júnior é o teu filho, é o filho que o gay não tem, então é um nome de todo homem, mas ele dá essa conotação de ser jovem também. $\mathrm{O}$ gay de 50 anos quer se sentir com 30 ". Indo ao encontro dessa mesma lógica, Hélio Filho ${ }^{45}$, último editor e publisher do veículo, reitera que, "sendo um sonho de todo mundo", apesar do leitor talvez não possuir a idade vendida por Junior, ele compra aquela idade. "A pessoa não tem, mas ela consome aquela idade [...] Junior sempre foi teenager, jovem, imberbe, colorida".

Naquilo que se refere, então, aos ensaios fotográficos que integravam a revista, ainda que em alguns momentos pudesse trazer homens mais velhos, a tônica preponderante do veículo era, de fato, trazer homens jovens e, agregados a esse elemento, sujeitos com uma performance de gênero viril. $O$ texto que acompanha as fotografias do modelo Felipe Donatti, de então vinte anos, por exemplo, ressalta, ao apresentá-lo, o seu olhar marcante, a sua voz firme e máscula e o seu corpo de deus grego. Todos esses elementos, pois, constituídos verbal e imageticamente, diziam dos corpos que, de fato, poderiam importar e para quais deles o desejo era legitimado. A capa dessa edição (Figura 2) pode ser observada abaixo.

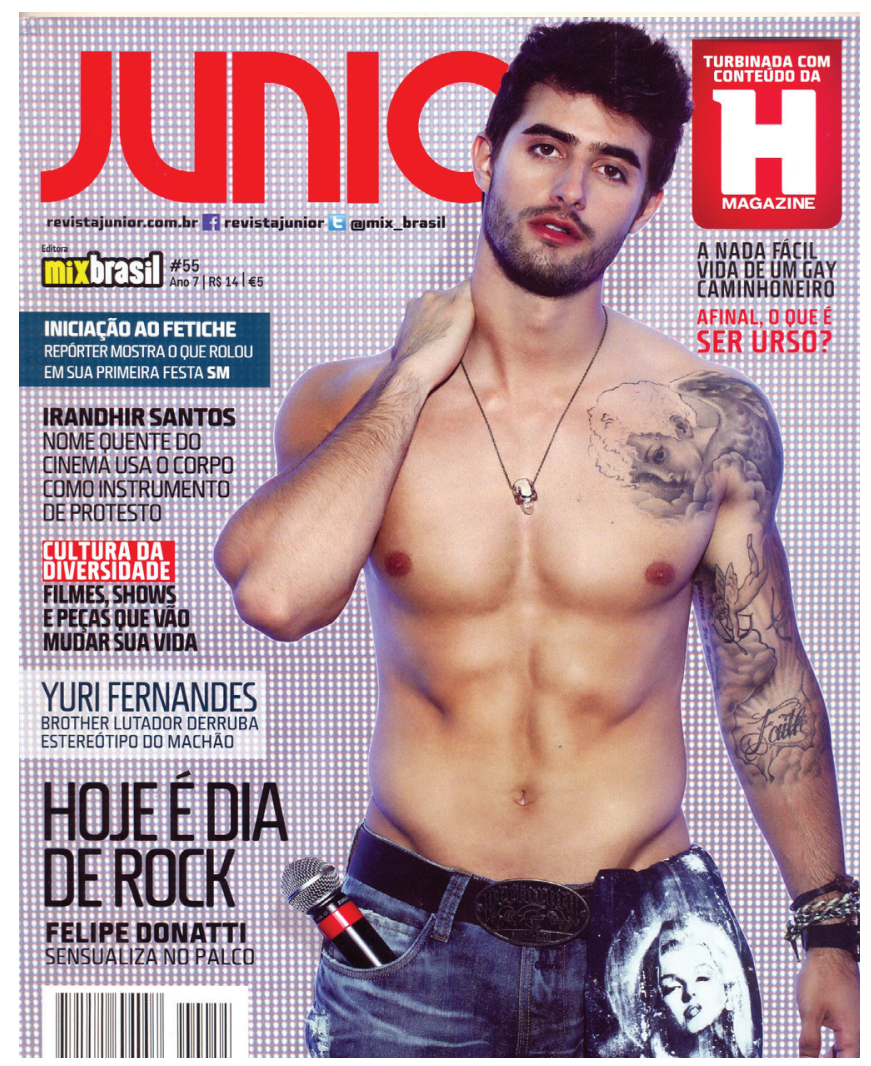

Figura 2 - Porque hoje é dia de rock Fonte: Junior (2013)iii.

iii Junior (Editora Mix Brasil); 2013;7:55. 
Para além da juventude que se constituía em desejo, por meio dos corpos que se expunham nas páginas de Junior, igualmente, a juventude assinalava grande parte daqueles corpos que se materializavam em textos e em reportagens da revista. Sob a editoria Test Drive ou, ainda, sob a editoria Minha Primeira Vez, repórteres vivenciavam experiências muitas vezes inéditas para si. Foi assim, por exemplo, que o repórter Gean Gonçalves foi, pela primeira vez, a uma festa voltada à comunidade ursina; que esteve em uma sauna gay e que em uma festa de descamisados ficou sem camisa, e que o repórter Nelson Neto ${ }^{46}$, por sua vez, foi a uma primeira festa fetichista.

"A princípio tirei a camiseta e a calça, fiquei de camisa. Mas logo a casa fica cheia e todos os frequentadores seguem rigorosamente a regra dresscode. Você vai se sentir um peixe fora d'água se não se sentir no clima "luxúria". Boa música, bons boys, pista cheia, drinques bem feitos e gente bacana. Tudo corre bem, troco alguns olhares com o pessoal que passa por mim, até que estou no bar pedindo minha cerveja e vejo um índio, meio cowboy, com adereços que incluíam franjas de couro no antebraço que me lembrava o estilo Ney Matogrosso. Dei aquela erguida de sobrancelha, fixei os lábios fazendo um biquinho labial, pisquei, disse um: "oi”. Ok, paquerar com uma cueca estilo macacão de luta greco-romana não é tão sexy, ainda mais quando o pretendente ainda está meio cowboy meio índio com franjas no antebraço que me lembravam o Ney Matogrosso, mas eu curti o boy. Bonito, pegada forte, enfim, meu número”46.

Ainda em um movimento que, a nosso ver, diz de uma cumplicidade com um projeto de masculinidade hegemônica, em Junior parece existir uma concepção inquestionável de que por serem gays, os leitores deveriam estar interessados em ter, fundamentalmente, dentre os assuntos abordados na revista, 'aventuras' sexuais e/ou discussões que apontassem para uma vivência sexual intensa e, mais do que isso, para indicações das formas possíveis de obtê-la. Bichas do Mato - matéria realizada por três repórteres em três diferentes parques do Rio de Janeiro, de São Paulo e de Salvador, acerca da 'pegação' nesses lugares - e No banheirão dos Estádios - em que, novamente três repórteres vão a jogos de futebol no Pacaembu, no Morumbi e no Engenhão, a fim de confirmar as lendas que cercam banheiros de estádios de futebol - são então ilustrativas.

"Enquanto fazia caminhada, reparava na movimentação local. Aos poucos a terceira idade e alguns atletas foram sumindo. Daí comecei a perceber que os caras começavam a ficar com olhares nervosos. Além disso, vez ou outra eu passava por um atleta mais interessante e, ao virar a cabeça para conferir, via que ele fazia o mesmo. Sinal clássico de pegação. Como eu era o novato ali, teria que esperar alguma alma caridosa disposta a me apresentar às quebradas do bosque. E não demorou muito para que um cara encharcado de suor e com coxas grossas me desse o sinal (leia-se olhar para mim). E lá fui eu!" 47.

"Três homens estavam no banheiro. Um dos rapazes era meio feioso, mas o outro era super 'fazível': negro, uns 25 anos no máximo, calça de moletom e boné. Me coloquei no mictório em frente ao reservado do bonitinho. Sempre de olho no gato do reservado. Ele parecia tímido ou inseguro com a possibilidade de alguém aparecer e ver toda aquela ação. Foi quando resolvi mandar tudo às favas e praticamente entrei no reservado junto com ele, com as calças até o joelho. 'Fica esperto para ver se vê alguém', me pediu. Os outros dois que estavam no banheiro obviamente assistiam a tudo. Quando eu já estava completamente envolvido na carícia que estava recebendo, tomamos um baita susto, todos os quatro: do nada, a torcida solta um daqueles 'uhhhhhh' típicos de quando um gol é perdido. Mas foi tão alto e parecia ter sido tão perto de nós que cortou todo o clima. O cara não levou mais do que uma fração de segundo para levantar, puxar as calças para cima e deixar o banheiro. Os outros dois também acharam melhor sair dali e eu fiquei só" 48 .

Todos esses textos, a modelo daquilo que ocorreria em revistas juvenis, sugerem uma pouca experiência por parte dos leitores e, ainda, expõe que seria na revista que o conhecimento de como ser bem-sucedido nesse terreno da prática sexual poderia ser alcançado. Richard Miskolci' ${ }^{49}$, em uma posição que coaduna com aquilo que se observa aqui, percebe, em Junior, uma revista que, ainda que não voltada apenas para adolescentes, dirigir-se-ia a homens que adotariam "modelos corporais e comportamentais aprisionados em um culto da juventude-imaturidade”. Para além da manutenção de um corpo que dissesse de determinada faixa etária e de um valor a ela atrelado, portanto, a eterna juventude de Junior, ainda, seria ratificada via 
construções textuais que alocariam os leitores na posição de aprendizes/seguidores. Gays, jovens ou nem tão jovens, que veriam em seus textos-manuais uma rota segura.

Cuide-se como um homem! Não fique velho e nem careca!; Fique mais atraente! Pareça 10 anos mais jovem em 10 minutos por dia! Comece a viver! Aumente 10 anos a sua vida! A juventude, igualmente, representa um importante valor para a revista Men's Health Portugal. Ao descolar-se de um determinado estágio do desenvolvimento, e ao ser convertida em meta a ser alcançada, a velhice, e seus indicativos, passam a ser tomados como reflexos de más práticas e não mais como sintomas naturais. Trechos de algumas reportagens veiculadas na revista, a fala de Pedro Lucas, editor de MH Portugal e a contracapa de uma edição especial da revista (Figura 3) dizem desses elementos.

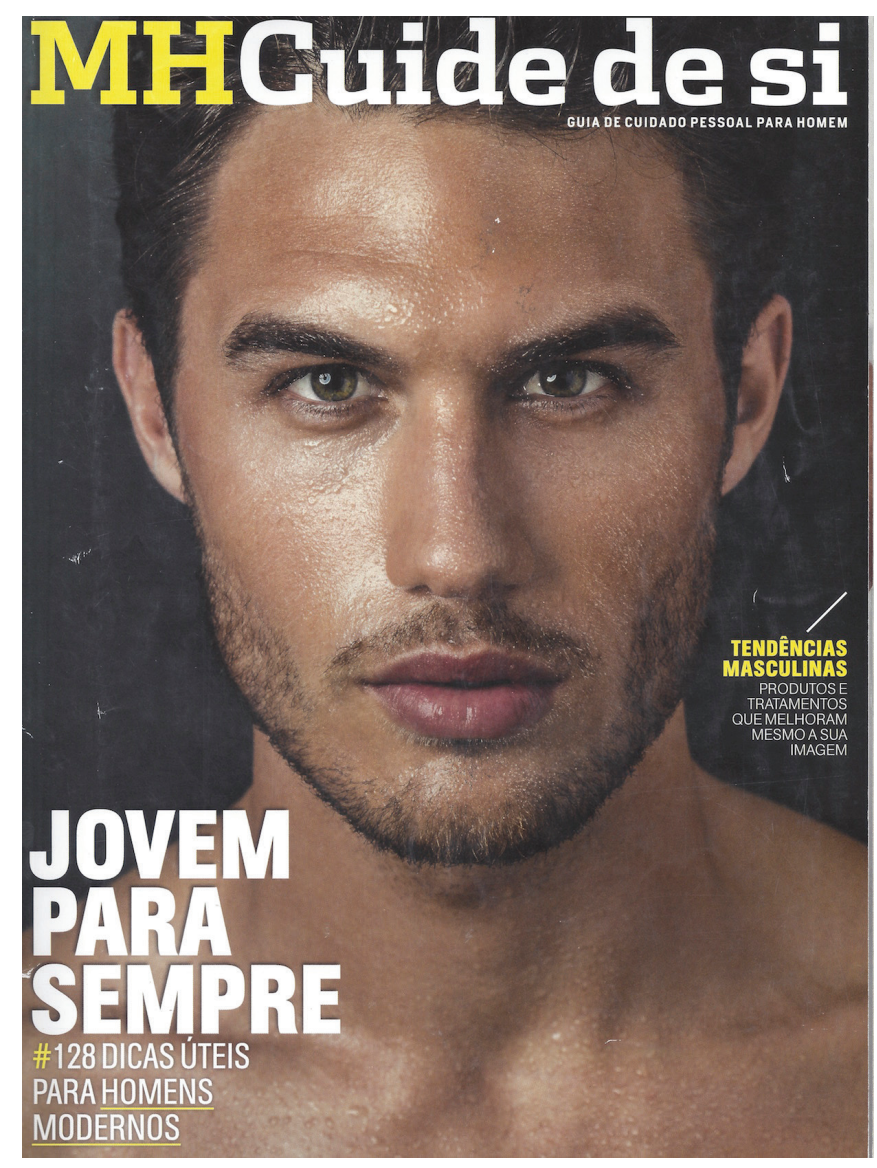

Figura 3 - Jovem para sempre

Fonte: Men's Health (2015)iv.

"Bem-vindo ao melhor guia de cuidado pessoal masculino. É com orgulho que somos a revista referência nessa área, pois nunca hesitamos em defender que o homem se deve cuidar para se sentir mais bonito, seguro e jovem"50.

"Há algo que preocupe mais os homens do que perder cabelo? Não! Sabemos o que precisa de acrescentar, diminuir e multiplicar na sua rotina diária para ter um resultado excelente. Saiba como travar essa batalha" ${ }^{1}$.

"Deixe-me dizer que o ser jovem para sempre se refere a forma do tratamento, ou seja, basicamente queremos dizer que há produtos, que há tratamentos, que há uma série de dicas e de coisas que homem pode fazer no seu dia a dia [...] A juventude, então, está a ir ao encontro completamente daquilo que são os ideais da MH: no cuidado, no treino, na alimentação. Os homens querem ser mais saudáveis, querem viver mais, querem ter mais estilo, querem se sentir melhor com eles mesmos! Querem ter o prazer de ser homem. A juventude para nós, portanto, é nosso porto seguro e aquilo que temos que trabalhar"52.

iv Men's Health (Editora Motorpress); 2015; 14:168. 
Para além de uma juventude que se resumiria à constituição de determinado modelo corporal/estético jovem, de maneira semelhante ao que acontece em Junior, ao abordar o sexo e o relacionamento (sempre a partir de uma pressuposta - e abrangente - heterossexualidade dos leitores), Men's Health Portugal também tende a encarar seu leitor como alguém que precise de pistas sobre como proceder no instante da sedução, quase que como um 'novato' (adolescente, talvez?). Aprender a ser capaz de conquistar a mulher desejada, bem como estar apto para lhe garantir, posteriormente, intensa satisfação sexual, consiste em uma questão que é posta como essencial para que uma posição de poder hegemônica seja alcançada e para que o prazer de ser homem (slogan da revista) seja plenamente vivenciado pelo leitor.

"Se há algo comum a qualquer solteiro é a rapidez com que afirmam que este seu status garante acesso VIP ao mundo do sexo. Como não existe compromisso com nenhuma mulher, é possível "picar" o cardápio inteiro sem se preocupar com o pequeno almoço na cama, dizer "amo-te" a toda hora ou ter de provar vezes sem conta que a relação será eterna [...] A mais valia [para os casados] é a facilidade com que trocam a variedade pela qualidade. Quando a relação corre bem, qualquer contratempo desaparece por artes mágicas e, como vivem na mesma casa, acreditamos que a sua mulher esteja sempre pronta para alinhar consigo nas mais variadas brincadeiras sexuais" 53 .

"A vida não lhe parece mais fácil quando tem uma mulher nua e satisfeita a dormir em sua cama? Claro que sim! Estaria a mentir se dissesse o contrário. Para a maioria dos homens, atingir o orgasmo e ver a mulher ao lado feliz é mais do que o suficiente para considerar o sexo excelente. Para elas, o sexo é bom quando você se preocupa com o orgasmo dela e quando sente que existe uma ligação. Há uma grande diferença, certo? Reforce essa intimidade!”’4.

Nesse cenário de buscas e de realizações de fantasias sexuais, igualmente, para além da relação direta com um projeto de masculinidade dominante, há que se ponderar sobre a relação que, aí, se estabelece com a juventude e com seus ideais. Men's Health Portugal inscreve os corpos que então mobiliza na máxima que Edgar Morin ${ }^{55}$ aponta como sendo a tônica da cultura de massa: "sejam belos, sejam amorosos, sejam jovens". Ao contribuir para o rejuvenescimento de uma sociedade, tal lógica retarda continuamente a velhice, causando um prolongamento da infância e da juventude junto ao adulto. A forte presença de uma lógica predatória no que se refere ao sexo, ao nosso ver, assim como é sustentáculo de uma masculinidade hegemônica, também o é de uma postergação e/ou adiamento da velhice.

Para Rebeca Seixas ${ }^{34}$, que volta sua atenção, mais especificamente, à versão brasileira de $\mathrm{MH}$, “os enredos sexuais propostos por Men's Health, além de manter a virilidade inquestionável e o controle masculino do que acontece na cama [...] buscam incutir no leitor um sentimento de expertise em relação ao prazer feminino". Tendo em vista as edições acessadas, bem como as falas de editor, repórteres e fotógrafo envolvidos em sua produção, apreende-se que postura similar se dá na edição portuguesa. Há que se saber como conquistar, há que se saber como proceder, há que se saber como 'dar' prazer às mulheres. Assim como fariam outras revistas juvenis ou então manuais de comportamento, a revista, na condição de dispositivo discursivo das masculinidades ${ }^{2}$, diz aos seus leitores como ser/estar enquanto homem eternamente jovem.

\section{Considerações finais}

Ainda que a questão do corpo que se insere dentro dos padrões estabelecidos de beleza seja relevante para a revista Sou Mais Eu, principalmente no que tange ao imperativo dos corpos magros, de modo geral, nessa revista, a passagem do tempo e o envelhecimento se constituem tanto socialmente como corporeamente. Percebemos que as fases da vida da mulher são, com frequência, associadas ao ciclo reprodutivo feminino: ainda que uma menina tenha 15 anos ao se tornar mãe, ela passa à fase adulta. Sobre as imagens, por se tratar de uma revista que busca contar histórias de suas leitoras, em especial de mulheres adultas das classes C, D e E, e por ser essencialmente composta por fotos de arquivo pessoal das narradoras, a Sou Mais Eu parece configurar de maneira única as preocupações que tem em comum com as revistas Junior e Men's Health Portugal. 
As questões que mais parecem importar passam pelas vivências cotidianas e seus desafios a serem superados, que, em sua maioria, operam na fixação das mulheres que narram a um prisma de feminino cristalizado. Ou seja, é requerido que, mesmo aos 15 anos, uma mãe se comporte como adulta e execute com êxito a cartilha da cultura do cuidado, que coloca as mulheres em uma constante doação de si (para filhos, maridos, pais etc.). Ao mesmo tempo, mulheres de classe média e com acesso à educação narram episódios mais associados aos marcadores de passagem de tempo relacionados à vida profissional, modelo geralmente encontrado nas narrativas masculinas. Mais uma vez, sinalizamos a força dos atravessamentos classe e gênero na configuração narrativa dessas mulheres.

Junior e Men's Health Portugal, em contrapartida, percebem o envelhecimento (ou o não envelhecimento, mais propriamente falando) a partir de uma lógica que insere o corpo como elemento central naquilo que se refere ao acesso a uma posição dominante. O corpo espetacular, tendo em vista o discurso movimentado e constituído nas publicações, bem como aquele acessado por meio de entrevistas com os seus produtores, é condição essencial para que uma masculinidade hegemônica possa se estruturar e se desenvolver. Para além disso, igualmente, a promoção de um estilo de vida e de um conjunto de práticas que digam de um culto à juventude mais uma vez reforça a tese de que para vivenciarem o prazer de ser homens (para empregar aqui o slogan da revista portuguesa) há que, necessariamente, não ser um velho.

Ou seja, envelhecer assume sentidos muito diferentes nos relatos a partir do gênero, classe e raça de quem narra, bem com o significado do termo, que implica questões mais encarnadas para alguns, enquanto outras ressaltam perspectivas mais sociais, ainda que a questão física do ciclo reprodutivo seja estruturante para que se entenda o que é tomado como uma mulher jovem e uma mulher velha. No caso do envelhecimento feminino, é possível notar também as questões axiológicas baseadas em uma moral patriarcal, já que ser mãe solteira aos 15 anos parece uma opção menos aceitável socialmente do que o casamento com o estuprador.

Ainda que a dimensão social do envelhecimento tenha se dado a ver com mais força nas páginas da revista Sou Mais Eu, a dimensão do envelhecimento do corpo que deve ser evitado é um traço comum entra as três revistas estudadas. Apagar os sinais do tempo e ostentar corpos cada vez mais magros e mais jovens são condições para os projetos de felicidade e sucesso proposto pelas narrativas e pelos discursos então acompanhados.

\section{Referências}

1. Machado FVK. Entre o público e o privado: dos sentidos historicamente movimentados e construídos por Veja sobre a velhice [dissertação]. São Leopoldo: Universidade do Vale do Rio dos Sinos; 2013.

2. Machado FVK. Homens que se veem: masculinidades em Junior e em Men's Health Portugal [tese]. São Leopoldo: Universidade do Vale do Rio dos Sinos; 2017.

3. Gonçalves JS. Sou Mais Eu entre duas matrizes de superação: configurações narrativas de questões de gênero em relatos autobiográficos femininos de superação [dissertação]. Belo Horizonte: Universidade Federal de Minas Gerais; 2017.

4. Ricoeur P. Tempo e narrativa. Vol. 1, A intriga e a narrativa histórica. Campinas: Papirus; 2010.

5. Leal BS. No embate entre estratégias e táticas, o fluir e a fabulação do acontecimento. In: Voguel $D$, Meditsch E, Silva G, organizadores. Jornalismo e acontecimento: tramas conceituais. Florianópolis: Insular; 2013. p. 135-158.

6. Farré M. El noticiero como mundo posible: estrategias ficcionales em la información audiovisual. Buenos Aires: La Crujía; 2004.

7. Carvalho CA, Sant'ana GAC. A tríplice mímeses como inspiração metodológica para a análise de produtos culturais. C\&S. 2013;35(1):227-250.

8. Butler J. Problemas de gênero: feminismo e subversão da identidade. São Paulo: Record; 2012. 
9. Rich A. Heterossexualidade compulsória e existência lésbica. Bagoas est gays gêneros sexual. 2010;4(5):18-44.

10. Preciado PB. Manifesto contrassexual. São Paulo: N-1 Edições; 2014.

11. Foucault M. História da sexualidade I: a vontade de saber. Rio de Janeiro: Edições Graal; 2011.

12. Carvalho CA. A tríplice mimese de Paul Ricoeur como fundamento para o processo de mediação jornalística. In: Anais do $19^{\circ}$ Encontro Anual da Compós; 2010 jul. 8-11, Rio de Janeiro. Rio de Janeiro: PUC-Rio; 2010.

13. Kohli M, Meyer J. Social structure and social construction of life stages. Hum Dev. 1986.;29(3):145-9.

14. Debert GG. A reinvenção da velhice: socialização e processos de reprivatização do envelhecimento. Edusp, 1999. p. 51.

15. Silva LRF. Da velhice à terceira idade: o percurso histórico das identidades atreladas ao processo de envelhecimento. Hist Ciênc Saúde: Manguinhos. 2008 jan.-mar.;15:155-68.

16. Bourdieu P. Questões de sociologia. Rio de Janeiro: Marco Zero; 1983. Capítulo 12, A "juventude" é apenas uma palavra; p. 112-121.

17. Beauvoir S. A velhice. Rio de Janeiro: Nova Fronteira; 1990.

18. Barros MML. Velhice na contemporaneidade. In: Peixoto CE. Família e Envelhecimento. Rio de Janeiro: Editora FGV; 2004. p. 13-23.

19. Goffman E. Estigma: notas sobre a manipulação da identidade deteriorada. Rio de Janeiro: LTC; 2004.

20. Sartre JP. O ser e o nada: ensaio de ontologia fenomenológica. Petrópolis: Vozes; 2011.

21. Scalzo M. Jornalismo de revista. São Paulo: Contexto; 2008.

22. Benetti M. Revista e jornalismo: conceitos e particularidades. Capítulo 03. In: Tavares FMB, Schwaab R. A revista e seu jornalismo. Porto Alegre: Penso; 2013. p. 44-57.

23. Tavares FMB, Schwaab R. Revista e comunicação: percursos, lógicas e circuitos. Capítulo 02. In: Tavares FMB, Schwaab R. A revista e seu jornalismo. Porto Alegre: Penso; 2013. p. 27-43.

24. Buitoni DS. Revista e segmentação: dividir para reunir. Capítulo 07. In: Tavares FMB, Schwaab R. A revista e seu jornalismo. Porto Alegre: Penso; 2013. p. 107-118.

25. Marín-Díaz DL. Autoajuda, educação e práticas de si: genealogia de uma antropotécnica. Belo Horizonte: Autêntica editora; 2015.

26. Mendonça CMC. E o verbo se fez homem: corpo e mídia. São Paulo: Intermeios, Casa de artes e livros; 2012.

27. Feitosa RAS. Linhas e entrelinhas: homossexualidades, categorias e políticas sexuais e de gênero nos discursos da imprensa gay brasileira [tese]. Fortaleza: Universidade Federal do Ceará; 2014.

28. Ferreira TF. Cabral segue sua nau: as representações da homossexualidade masculina luso-brasileira nas revistas Junior e Com' Out [dissertação]. Braga: Universidade do Minho; 2014.

29. Falcão F. Entrevista com o jornalista Felipe Falcão. 17/12/2014. Entrevistado por Felipe Viero Kolinski Machado. Residência do entrevistado. São Paulo. Duração: 60 min.

30. Men's Health Media Kit [Internet]. New York; 2016 [cited 2017 Dec 31]. Available from: https:// menshealthmediakit.s3.amazonaws.com/MH_MEDIA\%20KIT_103116.pdf

31. Seixas RBS. "Seja homem!": construção de masculinidade na revista Men's Health Brasil [dissertação]. Santa Maria: Universidade Federal de Santa Maria; 2012.

32. Januário SMBB. As masculinidades contemporâneas e a sua representação nos media: as revistas de estilo de vida masculina Men's Health com edição em Portugal e no Brasil [dissertação]. Lisboa: Universidade Nova de Lisboa; 2009.

33. Duarte JF. Representações dos corpos masculinos na revista Men's Health. Ci Soc Unisinos 2012;48(3):235-47. 
34. Sibilia P. Em busca da felicidade lipoaspirada: agruras da imperfeição carnal sob a moral da boa forma. In: Freire Filho J, organizador. Ser feliz hoje: reflexões sobre o imperativo da felicidade. Rio de Janeiro: Editora FGV; 2010. p.195-212

35. Ribeiro SSP. Sou quem eu quiser com lentes coloridas! Sou Mais Eu (Editora Caras). 2015:Ed. 443:20.

36. Martins RAF. A aporética da temporalidade em Santo Agostinho e Paul Ricoeur. R Ci Humanas. 2010 dez.;11(17):57-100.

37. Franch M. Três histórias: tempo, juventude e gênero em contextos de exclusão social. In: Souza MF, organizador. Desigualdades de gênero no Brasil: novas ideias e práticas antigas. Belo Horizonte: Fino Traço; 2010:209-238.

38. Hareven T. Synchronizing individual time, family time and historical time. In: Bender J, Wellbery DE. Chronotypes: the construction of time. Standford, California: Standford University Press; 1991:167-182.

39. Santos LS. Fui obrigada a casar com o meu estuprador aos 13 anos. Sou Mais Eu (Editora Caras). 2015:Ed. 454:15.

40. Carvalho F. Tatuo mulheres com corpos marcados pela violência. Sou Mais Eu. (Editora Caras). 2015:Ed. 457:15.

41. Bauman Z. O mal-estar da pós-modernidade. Rio de Janeiro: Jorge Zahar; 1998.

42. Connel RW. Masculinidades. México: Universidad Nacional Autónoma de México, Coordinación de Humanidades, Programa Universitário de Estudios de Género; 2003.

43. Costa JF. Notas sobre a cultura somática. Rio de Janeiro: Garamond, 2005.

44. Vesceslau P. O (super) mercado gay. Imprensa. 2007; online.

45. Filho H. Entrevista com o jornalista Hélio Filho. 15/12/2014. Entrevistado por Felipe Viero Kolinski Machado. Residência do entrevistado. São Paulo. Duração: 90 min.

46. Neto N. Primeiro fetiche. Junior (Editora Mix Brasil). 2013;7(55):51-54.

47. Filho H, Dias F, Coutinho G. Bichas do mato. Junior (Editora Mix Brasil). 2012;5(40):46-49.

48. Dias F, Oliveira E, Alves I. No banheirão dos estádios. Junior (Editora Mix Brasil).2012;5(42):47-50.

49. Miskolci R. Reflexões sobre a revista Junior [Internet]. Quereres: Núcleo de Pesquisa em Diferenças, Gênero e Sexualidade. São Carlos: UFSCAR; 2010 [citado em 2018 jun. 13]. Disponível em http://www. quereres.sites.unifesp.br/2010/06/reflexoes-queer-sobre-a-revista-junior/

50. Cuide-se como um homem. Men's Health Portugal (Editora Motorpress). 2015;14(168):04-08.

51. Equação perfeita. Men's Health Portugal (Editora Motorpress). 2015;14(174):110-115.

52. Lucas P. Entrevista com o jornalista Pedro Lucas. 09/06/2015. Entrevistado por Felipe Viero Kolinski Machado. Redação da Revista Men's Health Portugal. Duração 70 min.

53. Parreira J. Casar ou não casar? Men's Health Portugal (Editora MotorPress). 2015;14(166):96-99.

54. Lopes S. 21 segredos para sua verdadeira satisfação. Men's Health Portugal (Editora Motorpress). 2016;15(177):92-95.

55. Morin E. Cultura de Massa do século XX: o espírito do tempo. Vol. 1, Neurose. Rio de Janeiro: Forense Universitária. 1997. 